\title{
Annual Report Readability and Earnings Management: Evidence from Chinese Listed Companies
}

\author{
Jinfeng Cheng \\ Lecturer \\ School of Economics and Management \\ North China University of Technology \\ Beijing, 100144 \\ Chang $\mathrm{Xu}$ \\ Postgraduate \\ School of Economics and Management \\ North China University of Technology \\ Beijing, 100144
}

\author{
Jixin Zhao \\ Dean, professor \\ School of Economics and Management \\ North China University of Technology \\ Beijing, 100144 \\ Haocheng Gong \\ Postgraduate \\ School of Economics and Management \\ North China University of Technology \\ Beijing, 100144
}

\begin{abstract}
This paper attempts to find the connection between earnings management and the readability of annual reports. We use STATA15.0 to search data of China's stock market annual report from 2012 to 2016. This study is based on 1163 listed companies in China stock market, and use Software developed by $s$ Taiwan scholars, it can generate a FOG INDEX assessing the readability of the annual report. We measure earnings management using the modified Jones model and adjusted cash flow accounting. The results show a significant positive correlation be twe en manipulative accruals and the FOG INDEX.
\end{abstract}

Keywords-earnings management, annual report readability, management discussion and analysis (MD\&A)

\section{INTRODUCTION}

Corporate disclosure usually consists of three elements: what, when, and how (Curtis, 2004). Its effectiveness depends on readability and comprehensibility. In the traditional company annual report, textual information accounts for about $80 \%$ of the length. It can be seen that in order to obtain useful information from the annual report, it is necessary to understand a large textual statement. However, with the improvement of the information disclosure system and regulatory requirements, the annual reports of listed companies are getting longer and longer, and they are full of professional slogans. The US Securities and Exchange Commission have long focused on the concise disclosure of listed companies' annual reports. Cox, the chairman of the US Securities and Exchange Commission, emphasized the importance of quantifying the readability of annual reports of listed companies.[3]

In the disclosure of annual report information, Management discussion and analysis (MD\&A) has become an important way for many investors to understand the operation and financial situation of enterprises. MD\&A is an important part

This paper is supported by the Advantage Discipline Project of North China University of Technology (XN058 ). of the annual report of the board of directors, which is the eighth section of the annual report of the listed companies in China. It requires the management to further explain and analyze the important historical information in the current financial statements and annotations of the company, and from the perspective of the company's management, to make the next year's business plan and the possible future development of the company. It is worthy of our attention to study the readability of MD\&A and explore its internal relationship with earnings management behavior so that it can be understood by more investors. In this paper, we try to answer the following question: Does the complexity of MD\&A in the annual report relate to earnings management? [4]

The rest of this paper is as follows: The second part introduces the theoretical environment of the relationship between annual report readability and earnings management. The third part introduces the sample and methodology used, followed by the fourth part gives the results and discussion. The last part summarizes the paper.

\section{THEORETICAL DEVELOPMENT AND HyPOTHESIS}

Due to the separation of ownership and management rights, the inconsistency between shareholders and agents, coupled with information asymmetry, will create agency problems. Fama and Jensen's (1983) showed that under the separation of ownership and management rights, if the company's decision-making management power and decision-making control are separated, when the performance declines and the stock price falls, the management will have pressure to change its behavior.

Therefore, the direct consequence of the separation of ownership and control is that managers take measures to maximize their interests while harming the interests of shareholders. According to Merkl-Davies and Brennan (2007), 
management can manipulate descriptive disclosures through seven methods: readability, rhetoric, subject, typographic structure, performance comparison, numerical selection, and performance attribution. Therefore, companies may use different methods to deal with the content and expression of information, especially using the so-called "impression management”. In this way, companies can adjust the difficulty of reading (such as making the article more difficult to read) or adopt Rhetorical techniques (such as using persuasive statements) to deal with verbal information. The purpose of adjusting the difficulty of reading is to cover up the bad news. This leads to financial reports becoming less and less credible.[2]

Of course, not all companies are like this. Rutherford (2003) argues that under information asymmetry, well-functioning companies attempt to demonstrate the superiority of their company's situation by disclosing readable information with high definition, while companies that operate poorly use complex language to blur negative news.

$\mathrm{Li}(2008)$ [7] shows that there is a negative correlation between the readability of corporate financial reports and financial performance, that is, the better the financial performance, the more readable the financial report, and the poorer financial performance of the enterprise means lower Financial report readability. However, the readability of lower financial reports is due to management's use of complex disclosure methods to conceal performance, or because the bad news itself is more difficult to communicate, which is not clear. The predecessors' literature provides two possible explanations for the negative correlation between the readability of financial statements and financial performance, namely, confusion theory and ontology.[5]Confusion theory believes that management deliberately adopts complex disclosure methods to make financial statements more concealed in order to achieve the purpose of concealing their true performance. Ontology believes that bad news itself is more difficult to communicate.[6] The ontological view is the null hypothesis of this paper.

\section{RESEARCH DESIGN}

\section{A. Sample Selection and Data Source}

This article uses stata15.0 to crawl the annual reports of listed companies in all non-financial industries between Shenzhen and Shanghai in 2012-2016, and then took its management discussion and analysis as the initial research object, and removed the sample of incomplete data. The selected sample must be based on the following principles: (1) Excluding the annual report of the newly listed company. (2) Considering that ST may have extreme values. (3) Excluding companies with incomplete financial data disclosure and sample companies with abnormalities in relevant indicators. This resulted in a sample of 5,196 companies-annual observations. In order to alleviate the influence of the outliers on the parameter estimation, the observation values belonging

$$
\begin{gathered}
T A_{t} / A_{t-1}=\alpha_{1}\left(1 / A_{t-1}\right)+\alpha_{2}\left(\square R E V_{t} / A_{t-1}-\square R E C_{t} / A_{t-1}\right)+\alpha_{3}\left(P P E_{t} / A_{t-1}\right)+\varepsilon \\
N D A_{t}=\alpha_{1}\left(1 / A_{t-1}\right)+\alpha_{2}\left(\square R E V_{t} / A_{t-1}-\square R E C_{t} / A_{t-1}\right)+\alpha_{3}\left(P P E_{t} / A_{t-1}\right)
\end{gathered}
$$
CSMAR database. to the continuous explanatory variables at the 1st and 99th percentiles of the distribution are subjected to a winsorize process. Other sources of data are the CCER database and the

\section{B. Research Models and Variables}

Drawing on Biddle al. (2009), Aymen Ajinaa. et al. (2016), Kin Lo et al. (2017), Cheng Xinsheng et al[1]. (2015), etc., the following model was established:

$$
\text { Readability }=\beta_{1}+\beta_{2} E M+\beta_{3} \text { Control }+\varepsilon
$$

Interpreted variable: Readability. The analysis of annual report readability indicators such as number of words, complex words, frequency of polysyllabic words, etc., is measured by the FOG INDEX. The Gunning FOG INDEX is an index proposed by American professor Robert Gunning in 1952. The index can examine the difficulty of reading an article in terms of the number of words, the difficulty, the number of complete thoughts, and the average sentence length.

FOG INDEX $=0.4$ [(total number of words / total number of sentences $)+($ long words * number / total number of words)

This index is often used to measure the ease of reading an article. It requires a reader (in the original English-speaking, Chinese does not have long words, English long words mainly refers to multi-syllable words) how many years of formal education. What is the index value of an article, it means that it needs a few years to understand. The lower the FOG INDEX value of an article, the easier it is for readers to understand. The relationship between the FOG INDEX and the difficulty of reading is as follows: an index greater than 18 means that the text is unreadable; $14-18$ is a difficult type; $12-14$ is an ideal type; $10-12$ is an acceptable type; 8-10 is a simple type.

The number of words in each sentence is calculated as the ratio of the total number of words divided by the number of sentences. A complex word is a word with three or more syllables. Longer sentences and a higher proportion of complex words increase the FOG INDEX, which means less readability. The FOG INDEX has been widely used and is increasingly used in the accounting literature.

The FOG INDEX analysis index is derived from the Chinese text analysis system of Taiwan Normal University. The method is to use the web version of the annual report readability analysis system http://www.chinesereadability.net to select relevant indicators, and then calculate according to the formula.

Interpret Variables: Earnings Management (EM): We use two methods to measure: the Jones model modified by Dechow et al. (1995) and the Modified Cash Accounting (MCA) proposed by Ohlson and Aier (2009) to estimate the maneuverability profit. To measure earnings management. 


$$
D A_{t}=T A_{t} / A_{t-1}-N D A_{t}
$$

Variable description: $T A_{t}=N T_{t}-C F O_{t}, N T_{t}$ is the net profit of the t-th period, $C F O_{t}$ is the net cash flow from operating activities in the t-th period, $N D A_{t}$ is the t-term non-manipulative accruals after the adjustment of the total assets at the end of the $\mathrm{t}-1$ period, $A_{t-1}$ is the total assets at the end of the t-1 period, $\triangle R E V_{t}$ :the difference between the income from the main business of the t-th and $\mathrm{t}-1$ periods, $P P E_{t}$ is the original value of the fixed assets at the end of the period $t$, $\triangle R E C_{t}$ is the difference between the accounts receivable of the $\mathrm{t}$-th and $\mathrm{t}-1$ periods.

The main feature of the MCA model is that it can be quickly converted into cash and risk-free subjects in the subject of assets and liabilities through the relaxation of cash definitions, and is amended to be broadly defined as "cash and cash equivalents” according to Ohlson and Aier (2009). In the nine steps proposed, the required information is taken from the four financial statements and compiled into a cash surplus table. The bottom line data obtained is the Comprehensive Cash Earnings (CCE), so analysts can compare and analyze the difference between the net profit of the income statement and the cash surplus of the cash surplus table and analyze the accounting surplus.

Control Variables: reference to existing literature, this paper controls the financial characteristics of corporate companies, corporate governance, and other factors that significantly affect the readability of annual reports. The meanings and measures of all variables are shown in the table below.

TABLE I. VARIABLE DESIGN AND DESCRIPTION

\begin{tabular}{|c|c|c|}
\hline Variable & variable code & Variable definition and Measurement \\
\hline Readability & Readability & Measured by the FOG INDEX \\
\hline \multirow{4}{*}{$\begin{array}{c}\text { Earnings } \\
\text { management }\end{array}$} & EM & Estimated with the modified Jones model \\
\cline { 2 - 3 } & MCA & $\begin{array}{c}\text { Compare and analyze and evaluate the accounting } \\
\text { surplus by using the difference between the net profit of the } \\
\text { income statement and the consolidated cash surplus of the } \\
\text { cash surplus statement }\end{array}$ \\
\hline \multirow{4}{*}{$\begin{array}{c}\text { Control } \\
\text { variable }\end{array}$} & State & Whether it is state-owned: yes=1, no $=0$ \\
\cline { 2 - 3 } & Lever & Average gearing ratio, total liabilities / average total assets \\
\cline { 2 - 3 } & Size & Company Size \\
\cline { 2 - 3 } & Age & Listing period \\
\cline { 2 - 3 } & ROE or DROE & Return on Equity and its changes \\
\hline
\end{tabular}

\section{EMPIRICAL RESULTS AND ANALYSIS}

\section{A. Descriptive Statistics}

The following table reports descriptive statistics for each variable. From the descriptive statistics of the main variables in this paper, the sample number is 900, the FOG INDEX average is 14.07 , the minimum value is 12.005 , and the maximum value is 21.43; the average value of earnings management is 0.018 , the minimum value is -0.03 , and the maximum value is 0.020 ; the mean value of MCA 488251, minimum 34852, maximum is 2318690 .

TABLE II. DESCRIPTIVE ST ATIST ICS FOR THE MAIN VARIABLES

\begin{tabular}{lccccc}
\hline Variable & Obs & Mean & Std.Dev. & Min & Max \\
Fog & All & 14.07 & 6.158 & 12.005 & 21.43 \\
\hline EM & All & 0.018 & 0.089 & -0.03 & 0.020 \\
MCA & All & 488251 & 34852 & 688921 & 2318690 \\
State & All & 0.5 & 0.5 & 0 & 1 \\
Roe & All & 4.519 & 6.254 & -21.48 & 37.39 \\
Lever & All & 0.332 & 0.805 & -3.688 & 13.44 \\
Size & All & 5.769 & 1.751 & 1.219 & 12.99 \\
Age & All & 15.58 & 5.614 & 0 & 25 \\
\hline
\end{tabular}

\section{B. Empirical Results and Analysis}

The table gives the results of multiple regressions to determine the impact of earnings management on the readability of the annual report. The results show that there is an important positive correlation between the manipulated profit level and the FOG INDEX derived from the model of Dechow et al. (1995). This confirms our conclusion that the company that conducts earnings management has a low readability of its annual report, and the published report has its high FOG INDEX.

This result confirms that when managers notice a decline in income, they exercise discretion in accounting choices or operational structures in order to reduce the risk of a company's perceived decline in profit levels. In this context, they have to try to cover up this behavior by increasing the complexity of the financial statements. That is, some listed company managers conceal and manipulate income by publishing less readable annual reports.

This result is consistent with the prediction of $\mathrm{Li}$ et al. (2011). Li confirmed that managers use earnings management to publish the hypothesis of less readable annual reports. The report believes that telling the truth is easier than lying, and it is not so easy to be convinced. Because the liar must ensure 
that the "facts" are consistent. Although earnings management is not fully categorized in many cases, in the case of management, this process does exist in listed companies, and some managers take the initiative to whitewash financial statements for personal purposes.

TABLE III. FOG INDEX AND EARNINGS MANAGEMENT REGRESSION RESULTS

\begin{tabular}{lcc}
\hline \multirow{2}{*}{ VARIABLES } & $(1)$ & $(2)$ \\
\hline EM & Fog & Fog \\
& $0.0453^{* *}$ & \\
MCA & $(8.0421)$ & $0.1001^{* * *}$ \\
& & $(6.0001)$ \\
State & & $-0.0192^{*}$ \\
& $-0.0619^{*}$ & $(2.0673)$ \\
Roe & $(2.0973)$ & $0.0125^{*}$ \\
& 0.0319 & $(0.0190)$ \\
Lever & $(0.1400)$ & $-0.003^{* *}$ \\
Size & 0.145 & $(3.008)$ \\
& $(0.3025)$ & $-0.209^{* * *}$ \\
Age & $-0.123^{* * *}$ & $(7.9231)$ \\
& $(8.5213)$ & $0.1612^{*}$ \\
Constant & 0.0264 & $(2.0812)$ \\
& $(0.6367)$ & 172.9 \\
Observations & 264.9 & $(620.0)$ \\
R-squared & $(830.5)$ & All \\
\hline
\end{tabular}

t-statistics in parentheses

*** $\mathrm{p}<0.01,{ }^{* *} \mathrm{p}<0.05, * \mathrm{p}<0.1$

\section{CONCLUSION}

The purpose of this paper is to study the impact of earnings management on the readability of annual reports. The results obtained indicate an important positive correlation between the level of manipulative accruals adjustment and the readability of the annual report, which can be demonstrated under both measures of earnings management. Companies that use earnings management techniques have poor readability for their annual reports. The results confirm that when managers find that profits are falling, they try to cover up the expected profits by increasing the complexity of the financial statements, with the aim of reducing the risk that the company may be exposed to.

In this context, they have to try to cover up their behavior by increasing the complexity of the annual report. It is not easy to make lies believe, because the liar must ensure that the "facts" are consistent. Although earnings management is not fully classified into dishonesty in many cases, this behavior does include some proactive behaviors that bias people's financial statements by natural growth or other means of management.

This confirms the importance of the readability of the annual report. The authorities must strengthen management and advice that is conducive to the readability of financial documents. The definition of information quality must take readability into account. Readability may lead the stock market to build confidence and attract investor. The complexity of accounting information has turned accounting into "black-box accounting.[8]" Whether as a forced experience or as a wise choice, accounting information must be transformed from complexity to clarity.

Our research has limitations. In fact, the readability of the annual report is studied as a whole, and does not take into account the nature of the information. In further research we will investigate the results of assigning a specific FOG INDEX to each type of information.

\section{REFERENCES}

[1] Cheng Xinsheng, Liu Jianmei, Cheng Yue. The benefits of mutual benefit or disguise: earnings manipulation and MD\&A non-financial information disclosure [J]. Accounting Research, 2015, (08): 11-18+96. [In Chinese]

[2] Luo Jinhui, Li Xue, Chen Huayang. 2017. Annual report readability and company agency costs. 2017 Annual Symposium of CJAR at Xiamen, work papers.[In Chinese]

[3] Xiao Hao, Zhan Lei, Wang Zheng. Review and Prospect of Empirical Research on Foreign Accounting Text Information[J]. Foreign Economics and Management, 2016, 38(09): 93-112.[In Chinese]

[4] Byoung-Hyoun Hwang, Hugh Hoikwang Kim, 2017. It pays to write well, In Journal of Financial Economics, 124, 373-394.

[5] Jaehyeon Kim, Yongtae Kim, Jian Zhou, 2017. Languages and earnings management, In Journal of Accounting and Economics, 63, 288-306.

[6] Kin Lo, Felipe Ramos, Rafael Rogo, 2017. Earnings management and annual report readability, In Journal of Accounting and Economics, 63, $1-25$.

[7] Li, Feng, 2008. Annual report readability, current earnings, and persistence. Journal of Accounting and Economics, 45, 221-247.

[8] Habib, Ahsan and Hasan, Mostafa Monzur, Business Strategies and Annual Report Readability (May 22, 2018). Accounting and Finance, Forthcoming. Available at SSRN: https://ssm.com/abstract=3183253 